\title{
Efeito do estradiol e da progesterona no desenvolvimento e na qualidade de embriões bovinos produzidos in vitro
}

[Effect of estradiol and progesterone on development and quality of bovine embryos produced in vitro]

\author{
A.N. Reis, L.K.X. Silva, A.O.A. Silva, J.S. Sousa, W.G. Vale \\ Central de Biotecnologia de Reprodução Animal - UFPa \\ Av. João Henrique de Carvalho, s/n \\ 68741-400 - Castanhal, Pará
}

\begin{abstract}
RESUMO
Avaliaram-se o desenvolvimento e a qualidade de embriões bovinos, cocultivados com células epiteliais do oviduto bovino (CEOBs) expostas ou não ao estradiol e à progesterona. Os ovócitos foram maturados in vitro por 24h e, então, fertilizados utilizando-se sêmen congelado, em estufa de $\mathrm{CO}_{2}$ a $5 \%$ e $38,5^{\circ} \mathrm{C}$. As CEOBs foram cultivadas em TCM-199 com ou sem estradiol ( $\left.E_{2}\right)$ (24 horas), nas mesmas condições da maturação e fertilização in vitro (MIV e FIV), e, em seguida, adicionadas aos diferentes grupos em $\mathrm{CR}_{2}$ com ou sem progesterona $\left(\mathrm{P}_{4}\right)\left(\mathrm{G} 1=\mathrm{P}_{4}+\mathrm{E}_{2}\right) ;\left(\mathrm{G} 2=\mathrm{E}_{2}\right) ;\left(\mathrm{G} 3=\mathrm{P}_{4}\right)$ e $(\mathrm{G} 4=$ controle). Após 18h da FIV, as células foram cultivadas nos diferentes sistemas. Nenhuma diferença $(\mathrm{P}>0,05)$ foi observada nas taxas de clivagem entre G1, G2 e G4 (53,5\%; 56,3\%; 51,7\%) e nos padrões de blastocistos (BLs) (29,3\%; 31,2\%, $28,7 \%)$. Índices menores $(\mathrm{P}<0,05)$ foram obtidos no G3 para ambas as variáveis $(34,5 \% ; 16,4 \%)$. G1 e G2 apresentaram taxas de eclosão maiores $(\mathrm{P}<0,05)$ que os outros grupos $(23,3 \%$; $23,2 \%)$, sendo $\mathrm{G} 4$ (19,3\%) diferente de G3 (16,1\%). Em G1, G2 e G3, o número de células nos BLs aumentou 125,9; 128,4 e 123,6, respectivamente $(P<0,05)$, em relação ao G4 $(112,5)$. Conclui-se que o tratamento das CEOBs com o $E_{2}$, nas primeiras 24 horas de cultivo, pode ser usado isoladamente ou em combinação com a progesterona, a fim de melhorar a qualidade de embriões bovinos produzidos in vitro.
\end{abstract}

Palavras-chave: bovino, embriões, hormônios

\begin{abstract}
The development and quality of bovine embryos co-cultivated with bovine oviduct epithelial cells (BOEC) supplemented or not with estradiol and progesterone were evaluated. Oocytes were matured and fertilized in vitro (MIV/FIV) $\left(5 \% \mathrm{CO}_{2} / 38.5^{\circ} \mathrm{C}\right)$. The BOEC were cultivated in TCM-199 with or without estradiol $\left(E_{2}\right)(24 h)$, in the same conditions of MIV/FIV. Presumptive zygotes were transferred to BOEC in suspension after in vitro maturation and fertilization of bovine oocytes with thawed percoll-selected sperm. The zygotes were cultivated in $C R_{2}$ medium containing or not progesterone $\left(P_{4}\right)\left(G 1=P_{4}+E_{2}\right)$, $\left(G 2=E_{2}\right),\left(G 3=P_{4}\right)$, and $(G 4=$ control). No significant differences $(P>0.05)$ were found in the cleavage rates among $G 1, G 2$, and $G 4(53.5 \%, 56.3 \%$, and $51.7 \%)$ as well as in relation to the blastocystis $(B L)$ rates $(29.3 \%, 31.2 \%$, and $28.7 \%)$. However, significant differences $(P<0.05)$ were observed in the G3 for both variables (34.5\% and 16.4\%). G1 and G2 showed hatching rates higher $(P<0.05)$ than the other groups (23.3\%; 23.2\%), being G4 (19.3\%) different from G3 (16.1\%) $(P<0.01)$. In the groups G1, G2, and G3, the total cell number of the BL increased $(125.9,128.4$, and 123.6) $(P<0.05)$ compared to G4 (112.5). These results demonstrate that the treatment of the BOEC with estradiol in first the 24 hours of culture can be used separately or in combination with the progesterone to improve the quality of bovine embryos produced in vitro.
\end{abstract}

Keywords: bovine, embryos, hormones

Recebido em 12 de dezembro de 2009

Aceito em 11 de outubro de 2010

E-mail: areis@ufpa.br 


\section{INTRODUÇÃO}

Inúmeras biotecnologias têm sido desenvolvidas para o melhoramento animal e para a conservação de material genético de alta qualidade em bovinos, como a inseminação artificial (IA), a transferência de embriões (TE) e a produção in vitro de embriões (PIVE), dentre outras biotécnicas mais complexas, que, além do significado científico, têm grande importância econômica e zootécnica.

A PIVE tem sido bastante utilizada como instrumento para exploração maximizada do potencial reprodutivo dos rebanhos, visto que esta biotécnica, associada à coleta de ovócitos a partir da punção folicular guiada por ultrassom (ovum pick up-OPU), permite o aproveitamento de um número muito maior de ovócitos de fêmeas de alto valor genético (Castilho et al., 2009).

Entretanto, vários trabalhos têm mostrado previamente que, enquanto a qualidade intrínseca do ovócito é o principal fator que afeta o rendimento de blastocistos bovinos durante o desenvolvimento in vitro, o principal fator a influenciar a qualidade dos blastocistos são as condições de cultura após fertilização (Rizos et al., 2003).

In vivo, os embriões permanecem no oviduto até o estágio de oito a 16 células, correspondendo a três ou quatro dias; em seguida, são transportados para dentro do útero, onde continuam a proliferar. As secreções desses dois segmentos diferem quanto à composição e concentração, variando durante esse trajeto e nas diferentes fases do ciclo estral, reguladas por esteroides ovarianos (Binelli et al., 2009; Saruhan et al., 2010). No desenvolvimento in vitro, estas modificações não ocorrem adequadamente na rotina do cultivo embrionário, sendo necessário que sejam realizadas melhoras na qualidade das condições de cultura que simulem essas variações, a fim de oferecer aos embriões um ambiente mais adequado in vitro (Miranda et al., 2007; Cevik et al., 2009). Desse modo, o objetivo deste estudo foi avaliar o efeito dos esteróides ovarianos, estradiol $\left(E_{2}\right)$ e progesterona $\left(\mathrm{P}_{4}\right)$, sobre as CEOBs, no desenvolvimento e na qualidade de embriões bovinos produzidos in vitro.

\section{MATERIAL E MÉTODOS}

O material coletado foi obtido de fêmeas bovinas de abatedouro, e o processamento do material foi realizado em Laboratório de Fertilização in vitro, da Central de Biotecnologia de Reprodução Animal, localizada no município de Castanhal, PA.

Folículos com 2 a $8 \mathrm{~mm}$ de diâmetro foram aspirados dos ovários, e foram selecionados os ovócitos que apresentassem cumulus com 1 a 3 camadas ou bem compacto (COC), assim como aspecto homogêneo do citoplasma. Após a seleção, os ovócitos foram distribuídos em gotas de meio de maturação (MIV) (TCM-199 bicarbonato, soro fetal bovino, FSH, LH e estradiol) e levados à estufa de $\mathrm{CO}_{2}$ a $5 \%$, com $38,5^{\circ} \mathrm{C}$ e alta umidade, onde os ovócitos permaneceram por 24 horas, para posterior fertilização in vitro (FIV).

As células epiteliais do oviduto bovino (CEOBs) utilizadas para o cocultivo foram obtidas raspando-se o oviduto no sentido istmoinfundíbulo pela parede externa. Após este processo, as CEOBs foram lavadas em meio TCM-199-hepes e soro fetal bovino (SFB) por meio de centrifugações sucessivas (10 segundos a 200G), sendo, então, retirada uma alíquota de células para ser distribuída em duas garrafas de cultura contendo o meio TCM-bicarbonato e SFB associado ou não ao $E_{2}(1 \mu \mathrm{g} / \mathrm{mL})$. Essas células permaneceram 24 horas nas mesmas condições da MIV, até sua utilização no dia seguinte.

Após as 24 horas de maturação, foram feitas novas lavagens das CEOBs, sendo o último sedimento dividido em gotas de cultivo de meio $\mathrm{CR}_{2}$ (Rosenkrans et al., 1993) suplementado com 10\% de SFB e albumina sérica bovina (BSA), associado ou não à $\mathrm{P}_{4}(100 \mu \mathrm{g} / \mathrm{mL})$.

Para a preparação do sêmen a ser utilizado na FIV, duas doses de sêmen foram descongeladas e avaliadas quanto a sua motilidade. Posteriormente, foram realizadas três lavagens em meio TALP, por meio de centrifugações sucessivas durante 10 minutos a 200G. O último sedimento de espermatozoides foi colocado em uma coluna de gradientes de percoll de 45 e $90 \%$ e centrifugado por 30 minutos a 200G. Os espermatozoides sedimentados foram lavados, 
mais uma vez, em meio TALP, e o sedimento final foi diluído em meio de FIV (Meio TALP, BSA, heparina e PHE), na proporção de 1:1. Desta solução foi retirada uma alíquota, para o cálculo da concentração, a fim de que as gotas de FIV tivessem $1 \times 10^{6}$ espermatozoides $/ \mathrm{mL}$.

Os espermatozoides permaneceram no meio de FIV durante duas horas, em estufa de $\mathrm{CO}_{2}$ nas mesmas condições citadas para a MIV, para que ocorresse a capacitação espermática.

Após 24 horas de MIV, os ovócitos que mostraram boa expansão das células do cumulus oophorus foram colocados nas gotas de fertilização já contendo os espermatozoides capacitados. Após 18 horas da fertilização, os ovócitos foram desnudos por meio de pipetagens sucessivas em TCM-199-hepes, até a retirada total das células que envolviam os supostos embriões. Posteriormente, os embriões foram transferidos para gotas de meio $\mathrm{CR}_{2}$ diferentes entre si de acordo com a presença de CEOBs, expostas ou não ao $E_{2}$ nas primeiras 24 horas de cultivo, e com a utilização ou não da $\mathrm{P}_{4}$ no meio de cultivo. $\mathrm{O}$ experimento foi constituído de três grupos experimentais $-\mathrm{G} 1=\mathrm{CEOB}+\mathrm{E}_{2}+\mathrm{P}_{4}, \mathrm{G} 2$ $=\mathrm{CEOB}+\mathrm{E}_{2}$ e $\mathrm{G} 3=\mathrm{CEOB}+\mathrm{P}_{4}-$ e um grupocontrole (sem hormônio) G4 = CEOB.

A clivagem foi feita no terceiro dia após a fertilização, a taxa de blastocistos (BLs) no sétimo dia, e, no nono dia, foi avaliada a porcentagem de BLs eclodidos. A avaliação da qualidade embrionária foi determinada pelo número total de células dos BLs expandidos de oito dias, utilizando-se o corante HOECHST 33342, por meio da incubação dos embriões durante 15 minutos, em uma solução de $1 \mu \mathrm{g} / \mathrm{mL}$ do corante diluído em meio TCM-199-hepes. Posteriormente, foi feita a fixação dos embriões sobre lâmina e lamínula, para a contagem do número de células pela microscopia invertida.

Dos dados obtidos, foi feita a análise de variância para avaliar os efeitos dos tratamentos (grupos), com nível de significância de 5\% e uso do teste Student-Newman-Keuls. O programa utilizado para todas as análises foi o BIOESTAT 2.0 (Ayres et al., 2000).

\section{RESULTADOS E DISCUSSÃO}

O tratamento das CEOBs com $E_{2}$ (G1 e G2) não melhorou $(\mathrm{P}>0,05)$ a proporção de zigotos que clivaram (53,5\% e 56,3\%), quando comparado com o G4 (sem a adição de hormônios) (51,7\%) (Tab. 1). Isto também pôde ser demonstrado por Fukui (1989), que obteve taxas de clivagem similares $(\mathrm{P}>0,05)$ entre o grupo-controle $(71,1 \%)$ e os demais grupos que continham somente $\mathrm{E}_{2}(62,0 \%)$ ou a associação de $\mathrm{E}_{2}$ e $\mathrm{P}_{4}$ $(63,1 \%)$. Xia et al. (1996) também observaram que $\mathrm{o} \mathrm{E}_{2}$ não afetou a proporção de zigotos clivados, quando adicionado somente antes da cocultura (0-48 h) (40,0\%).

Tabela 1. Efeito do tipo de cocultivo e do tratamento hormonal de células epiteliais do oviduto bovino (CEOB) sobre o desenvolvimento in vitro de embriões bovinos

\begin{tabular}{lcccc}
\multicolumn{1}{c}{ Tratamento } & $\begin{array}{c}\text { Taxa de } \\
\text { clivagem }(\%)\end{array}$ & $\begin{array}{c}\text { Taxa de BLs } \\
(\%)\end{array}$ & $\begin{array}{c}\text { Taxa de BLs } \\
\text { eclodidos (\%) }\end{array}$ & $\begin{array}{c}\mathrm{N}^{0} \text { células } \\
\text { dos BLs }\end{array}$ \\
\hline $\mathrm{CR}_{2}+\mathrm{CEOB}+\mathrm{E}_{2}+\mathrm{P}_{4}(\mathrm{G} 1)$ & $53,5 \pm 1,23 \mathrm{a}$ & $29,3 \pm 1,96 \mathrm{a}$ & $23,3 \pm 1,37 \mathrm{a}$ & $125,9 \pm 1,27 \mathrm{a}$ \\
$\mathrm{CR}_{2}+\mathrm{CEOB}+\mathrm{E}_{2}(\mathrm{G} 2)$ & $56,3 \pm 1,95 \mathrm{a}$ & $31,2 \pm 2,27 \mathrm{a}$ & $23,2 \pm 1,43 \mathrm{a}$ & $128,4 \pm 2,84 \mathrm{a}$ \\
$\mathrm{CR}_{2}+\mathrm{CEOB}+\mathrm{P}_{4}(\mathrm{G} 3)$ & $34,5 \pm 2,34 \mathrm{~b}$ & $16,4 \pm 1,85 \mathrm{~b}$ & $16,1 \pm 2,43 \mathrm{~b}$ & $123,6 \pm 4,81 \mathrm{a}$ \\
$\mathrm{CR}_{2}+\mathrm{CEOB}(\mathrm{G} 4)$ & $51,7 \pm 2,32 \mathrm{a}$ & $28,7 \pm 2,71 \mathrm{a}$ & $19,3 \pm 1,11 \mathrm{c}$ & $112,5 \pm 6,93 \mathrm{~b}$ \\
\hline
\end{tabular}

Valores com letras distintas, na mesma coluna, indicam diferenças $(\mathrm{P}<0,05)$ pelo teste Student-Newman-Keuls.

CEOB: célula epitelial do oviduto de bovino; $\mathrm{E}_{2}$ : estradiol; $\mathrm{P}_{4}$ : progesterona.

No entanto, esta similaridade de resultados entre G1, G2 e G4 quanto ao desenvolvimento dos embriões foi afetada nas taxas de eclosão provavelmente devido ao número reduzido de células dos BLs do G4 (112,5), visto que os padrões de eclosão diminuíram de 23,3 e 23,2 para $19,3 \% \quad(\mathrm{P}<0,05)$, respectivamente. Uma provável justificativa para esta diminuição é o não estímulo de $\mathrm{E}_{2}$ nas $\mathrm{CEOBs}$ nas primeiras 24 horas de cultivo do G4, visto que o oviduto regulado pelo estrógeno é responsável pela síntese direta de glicoproteínas (GP) e de fatores de crescimento (FC), biologicamente importantes para o desenvolvimento embrionário (Moreira et al., 2002; Lee et al., 2006), assim como pelo 
aumento na regulação dos receptores de estrógenos e progesterona (Ulbrich et al., 2003).

Xia et al. (1996) observaram que o $E_{2}$ também não afetou a proporção de zigotos clivados, quando adicionado somente durante o cocultivo (72-120h) (45,5\%). Talvez isto ocorra devido ao número reduzido de receptores de estrógeno presente nos embriões durante as primeiras clivagens, como demonstrado por Hou e Gorski (1993), que sugeriram a existência de grandes quantidades de receptores de estrógenos (REs) em ovócitos e zigotos. Segundo os autores, estes níveis declinavam a partir do estágio de duas células, alcançando os níveis mais baixos em embriões de cinco a oito células, porém não sendo mais detectados nos estágios de mórula, e somente reaparecendo na fase de BL.

No G3, os índices de clivagem foram os mais baixos do experimento (34,5\%), sendo diferentes dos índices do G1 $(\mathrm{P}<0,05)$, que também associava a progesterona ao meio de cultivo, no entanto as CEOBs haviam sido expostas ao $E_{2}$ (53,5\%). Esta diminuição na clivagem pode ter ocorrido pela mesma justificativa dada ao G4, ou seja, o não estímulo de $E_{2}$ nas $C E O B s$ nas primeiras 24 horas de cultivo, consequentemente a não regulação dos receptores de estrógenos e progesterona (Ulbrich et al., 2003).

As taxas de BLs obtidas nos grupos que continham CEOBs com $E_{2}$ (G1 e G2) não foram diferentes $(29,3 \%$ e $31,2 \%)(\mathrm{P}>0,05)$ das taxas do grupo-controle (28,7\%) (Tab. 1). No entanto, esses índices semelhantes foram afetados na eclosão, em que G1 e G2 (23,3\% e 23,2\%), que continham CEOBs expostas ao $\mathrm{E}_{2}$, mantiveram padrões mais altos que o G4 $(19,3 \%)(\mathrm{P}<0,05)$, assim como em relação à quantidade de células dos BLs (125,9; 128,4 e 112,5, respectivamente) $(\mathrm{P}<0,05)$.

A não estimulação das CEOBs com o $E_{2}$, no G4, talvez seja a provável causa para esses índices mais baixos de desenvolvimento dos embriões, visto que, como já citado anteriormente, o estrógeno estimula as células do oviduto a produzirem GP e FC, (Moreira et al., 2002; Lee et al., 2006), além de receptores de estrógenos e progesterona (Ulbrich et al., 2003).

Niemann e Elsaesser (1987) demonstraram alguns efeitos benéficos do $E_{2}$ sobre o cultivo de embriões suínos, quando observaram que a utilização de substâncias anti-estrogênicas no meio de cultura dificultava a transformação das mórulas tardias em BLs (21,5\%) e que o domínio da inibição desse desenvolvimento poderia ser feito pela suplementação do meio de cultivo com $1 \mathrm{nM}$ ou $100 \mathrm{nM}$ de $17 \beta$-estradiol $(62,5 \%$ e $80,0 \%)$.

Segundo Lee et al. (2006), o embrião e o oviduto possuem um mecanismo bioquímico necessário para a interação entre eles e, consequentemente, a melhoria na qualidade dos embriões. No entanto, esse mecanismo ainda não está bem esclarecido, e o que se sabe é que o oviduto, regulado pelo estrógeno, produz alguns fatores que favorecem essa relação, e que muitos dos seus receptores correspondentes estão presentes nos embriões, favorecendo o desenvolvimento.

Provavelmente, esses REs no embrião possam desempenhar um importante papel na biologia do desenvolvimento, pela ação direta do $E_{2}$ nos embriões durante o cocultivo, levando ao aumento na produção de FC pelos embriões, que agiriam autocrinamente, promovendo nova liberação desses fatores. Ainda, esses fatores agiriam nas CEOBs liberando GP e FC, que novamente atuariam sobre o embrião ou as CEOBs, formando uma cadeia simultânea de estímulos, promovendo o maior desenvolvimento das CEOBs e, consequentemente, dos embriões.

Os resultados obtidos com relação ao desenvolvimento dos embriões até BL em meios com cocultura de CEOBs assemelham-se aos encontrados por Nagao et al. (1994) (33,0\%) e Pavasuthipaisit et al. (1994) (28,3\%), independentemente da fase do ciclo estral na qual se encontravam as CEOBs. Todavia, são mais elevados que os obtidos por Pegoraro et al. (1998) (17,6\%) e Kamishita et al. (1999) (24,5\%), e mais baixos que os de Katska et al. (1995) (40,1\%).

A utilização da $P_{4}$ sem o $E_{2}(G 3)$ no cocultivo com CEOBs inibiu significativamente $(\mathrm{P}<0,05)$ os padrões de clivagem (34,5\%), de BL $(16,4 \%)$ e de eclosão (16,1\%), quando comparado com os resultados do G4 (51,7\%; 28,7\% e 19,3\%, respectivamente) (Tab. 1).

Estes dados são semelhantes aos obtidos por Pereira et al. (2009), que analisaram o efeito da 
$\mathrm{P}_{4}$ no desenvolvimento de embriões e observaram diminuição nos padrões de BLs de oito dias em sistema de cultura constituído de CEOBs quando se utilizou a $\mathrm{P}_{4}(\mathrm{CEOB}=23,7 \%$ e $\mathrm{CEOB}+\mathrm{P}_{4}=16,8 \%$ ). Este mesmo efeito foi demonstrado por Reggio et al. (1997), quando observaram que a adição de $\mathrm{P}_{4}$ ao meio $\mathrm{CR}_{1 \text { aa }}$ sem cocultivo diminuiu bastante 0 desenvolvimento dos embriões até BL (9\%), melhorando estes índices somente quando foram adicionadas CEOBs ao meio (15\%).

A $\mathrm{P}_{4}$, em particular, deve desempenhar também alguma ação negativa sobre o desenvolvimento embrionário até o estágio de BL, principalmente quando as células do oviduto não são expostas ao $\mathrm{E}_{2}$, visto que o meio contendo somente a progesterona diminuiu de forma significativa $(\mathrm{P}<0,05)$ os padrões de desenvolvimento no grupo G3.

Segundo Pereira et al. (2009), a progesterona induziu a um atraso no desenvolvimento do embrião, confirmado por índices mais baixos de desenvolvimento. No entanto, Clemente et al. (2009) afirmaram que a exposição in vitro do embrião a $\mathrm{P}_{4}$, na presença ou ausência de CEOBs, não afeta a proporção de embriões que se desenvolvem até $\mathrm{BL}$, assim como não interfere na quantidade de células dos BLs. Ghaemi et al. (2008) observaram, ainda, que os índices de desenvolvimento dos embriões melhoraram quando se aumentava a concentração de $\mathrm{P}_{4}$ no meio de cultivo de 5 para 20ng/mL. Fukui (1989) demonstrou que apesar de uma leve diminuição nas taxas de clivagem e de BLs nos grupos que continham somente $\mathrm{P}_{4}$ $(61,9 \%$ e $11,7 \%)$ ou esta associada a $E_{2}(63,1 \%$ e $17,3 \%)$, tal diferença não foi significativa $(\mathrm{P}>0,05)$ quando comparada com os dados do grupo-controle (71,1\% e 19,5\%).

A proporção de BLs que eclodiram em G1 e G2 não foi diferente $(\mathrm{P}>0,05)(23,3 \%$ e $23,2 \%)$, todavia estes dois grupos apresentaram diferenças $(\mathrm{P}<0,05)$ em relação a G3 e $\mathrm{G} 4$ $(16,1 \%$ e $19,3 \%)$, sendo G3 diferente $(\mathrm{P}<0,05)$ de G4 (Tab.1). Tais índices são similares aos obtidos por Kamishita et al. (1999) (24,5\%), entretanto não coincidem com os encontrados por Hawk e Wall (1994) (69,0\%) e Goff e Smith (1998) (41,8\%).
Os baixos índices de eclosão do G3 $(16,1 \%)$ podem estar relacionados às taxas de clivagem mais baixas no início do cultivo, e não a uma baixa capacidade dos embriões de eclodirem, visto que a $\mathrm{P}_{4}$ aumentou a quantidade de células dos BLs $(123,6)$, quando comparado com o G4 (sem hormônio) (112,5). Segundo Gordon e Dapunt (1993), o número de células é um dos possíveis mediadores da eclosão pela pressão exercida dessas células na zona pelúcida do BL. Estes resultados foram mais altos que os obtidos por Edwards et al. (1997) $(95,3)$ e Pegoraro et al. (1998) $(103,4)$.

G1 e G2 apresentaram índices de eclosão semelhantes $\quad(\mathrm{P}>0,05) \quad(23,3 \% \quad$ e $\quad 23,2 \%)$ provavelmente devido às quantidades similares de células presentes $(125,9$ e 128,4) $(\mathrm{P}>0,05)$.

Há poucos relatos do número de células de blastocistos produzidos in vitro e, quando efetuado, normalmente é apresentado o número médio de células, sem levar em conta o estádio ou a qualidade do blastocisto. Segundo Bernardi (2005), após o cultivo por cinco - oito dias, o número total de células relatado é de 50 a 100 para os estádios de blastocisto e blastocisto expandido, de 185 para blastocisto em eclosão e de 135 a 196 para blastocisto eclodido.

\section{CONCLUSÕES}

O tratamento das CEOBs com o estradiol nas primeiras 24 horas de cultivo pode ser usado isoladamente ou em combinação com a progesterona, a fim de melhorar a qualidade de embriões bovinos produzidos in vitro.

\section{REFERÊNCIAS BIBLIOGRÁFICAS}

AYRES, M.; AYRES Jr., M.; AYRES, D.L. et al. BioEstatic 2.0: Aplicações estatísticas nas áreas das ciências biológicas e médicas. Belém: Sociedade Civil Mamirauá, 2000. 272p.

BERNARDI, M.L. Produção in vitro de embriões ovinos. Acta Sci. Vet., v.33, p.1-16, 2005.

BINELLI, M.; PORTELA, V.M.; MURPHY, B.D. Dinâmica ovariana e eficiência reprodutiva: estado da arte. Rev. Bras. Reprod. Anim. Suppl., n.6, p.134-139, 2009.

CASTILHO, C.; RENESTO, A.; MUSTAFÁ, F.C. et al. Associação da MOET e OPU-PIV na produção de embriões bovinos. Cien. Anim. Bras., v.10, p.231-237, 2009. 
CEVIK, M.; SAGIRKAYA, H.; TAS, A. et al. Comparing in vitro embryonic development of bovine oocytes cultured in G1.3/G2.3 sequential culture media and CR1aa medium. J. Anim. Vet. Adv., v.8, p.11851189, 2009.

CLEMENTE, M.; DE LA FUENTE, J.; FAIR, T. et al. Progesterone and conceptus elongation in cattle: a direct effect on the embryo or an indirect effect via the endometrium ?. Reproduction, v.138, p.507-517, 2009.

EDWARDS, L.J.; BATT, P.A.; GANDOLFI, F. et al. Modifications made to culture medium by bovine oviduct epithelial cells: changes to carbohydrates stimuate bovine embryo development. Mol. Repr. Dev., v.46, p.146-154, 1997.

FUKUI, Y. Effects of sera and steroid hormones on development of bovine oocytes matured and fertilized in vitro and co-culture with bovine oviduct epithelial cells. J. Anim. Sci., v.67, p.1318-1323, 1989.

GHAEMI, S.R.; SALEHNIA, M.; VALOJERDI, M.R. The effect of progesterone and exogenous gonadotropin on pre-implantation mouse embryo development and implantation. Exp. Anim., v.57, p.27-34, 2008.

GOFF, A.K.; SMITH, L.C. Effect steroid treatment of endometrial cells on blastocyst development during coculture. Theriogenology, v.49, p.1021-1030, 1998.

GORDON, J.M.; DAPUNT, U. A new mouse model for embryos with a hatching deficiency and is use to elucidate the mechanism of blastocyst hatching. Fertil. Steril., v.59, p.1296-1301, 1993.

HAWK, H.W.; WALL, R.J. Improved yields of bovine blastocysts from in vitro-produced oocytes. Theriogenology, v.41, p.1585-1594, 1994.

HOU, Q.; GORSKI, J. Estrogen receptor and progesterone receptor genes are express differentially in mouse embryos during pre-implantation development. Proc. Ntl. Acad. Sci. USA, v.90, p.9460-9464, 1993.

KAMISHITA, H.; TAKAGI, M.; CHOI, Y.H. et al, Development of in vitro matured and fertilized bovine embryos co-cultured with bovine oviductal epithelial cells obtained from oviducts ipsilateral to cystic follicles. Anim. Reprod. Sci., v.56, p.201-209, 1999.

KATSKA, L.; RYŃSKA, B.; SMORAG, Z. The effect of co-culture system on development capacity of bovine IVM/IVF oocytes. Theriogenology, v.43, p.859-870, 1995.

LEE, K.F.; XU, J.S.; Lee, Y.L. et al. Demilune cell and parotid protein from murine oviductal epithelium stimulates preimplantation embryo development. Endocrinology, v.147, p.79-87, 2006.

MIRANDA, M.S.; CARVALHO, C.M.F.; CORDEIRO, M.S. et al. Sistemas alternativos de incubação e meios de cultivo para produção in vitro de embrião bovino. Rev. Bras. Reprod. Anim., v.31, p.218-223, 2007.
MOREIRA, F.; PAULA-LOPES, F.F.; HANSEN, P.J. et al. Effect of growth hormone and insulin-like growth factor-I on development of in vitro derived bovine embryos. Theriogenology, v.57, p.895-907, 2002.

NAGAO, Y.; SAEKI, K.; HOSHI, M. et al. Effects of oxygen concentration and oviductal epithelial tissue on in vitro matured and fertilized bovine oocytes cultured in protein-free medium. Theriogenology, v.41, p.681-687, 1994.

NIEMANN, H.; ELSAESSER, F. Accumulation of estrone by pig blastocysts and its potential physiological significance for blastocysts development in vitro. $J$. Reprod. Fertil., v.80, p.221-227, 1987.

PAVASUTHIPAISIT, K.; LHUANGMAHAMONGKOL, S.; TOCHARUS, C. et al. Porcine oviductal cells support in vitro bovine embryo development. Theriogenology, v.41, p.1127-1138, 1994

PEGORARO, L.M.; THUARD, J.M.; DELALLEAU, N. et al. Comparison of sex ratio and cell number of IVMIVF bovine blastocysts co-cultured with bovine oviduct epithelial cells or with vero cells. Theriogenology, v.49, p.1579-1590, 1998.

PEREIRA, R.M.; MARQUES, C.C.; BAPTISTA, M.C. et al. Embryos and culture cells: A model for studying the effect of progesterone. Anim. Reprod. Sci., v.111, p.3140, 2009 .

REGGIO, B.C.; LYNS, J.W.; GODKE, R.A. The effect of progesterone on the development of ivf-derived bovine embryos cultured in a semi-defined culture medium. Theriogenology, v.47, p.284, 1997.

RIZOS, D.; GUTIÉRREZ-ÁDAN, A.; PEREZGARNELO, S. et al. Bovine embryo culture in the presence or absence of serum: implications for blastocyst development, cryotolerance, and messenger RNA expression. Biol. Reprod., v.68, p.236-243, 2003.

ROSENKRANS Jr., C.F.; ZENG, G.Q; McNAMARA, G.T. et al. Development of bovine embryos in vitro as affected by energy substrates. Biol. Reprod., v.49, p.459462, 1993.

SARUHAN, B.; SAGSOZ, H.; AKBALIK, $M$. et al. Distribution of estrogen receptor alpha and progesterone receptor $\mathrm{B}$ in the bovine oviduct during the follicular and luteal phases of the sexual cycle: an immunohistochemical and semi-quantitative study. Biotech. Histochem., v.85, p.1-11, 2010.

ULBRICH, S.E.; KETTLER, A.; EINSPANIER, R. Expression and localization of estrogen receptor alpha, estrogen receptor beta and progesterone receptor in the bovine oviduct in vivo and in vitro. J. Steroid Biochem. Mol. Biol., v.84, p.279-289, 2003.

XIA, P.; RUTLEDGE, J.; WATSON, A.J. et al. Effect of estrogen-treated porcine ampulla oviductal epithelial cells on early embryonic development in vitro and characterization of their protein synthetic activity. Anim. Reprod. Sci., v.45, p.217-229, 1996. 